\title{
Ética e Serviço Social: fundamentos e contradições
}

\author{
Hélder Boska de Moraes Sarmento \\ Universidade Federal de Santa Catarina (UFSC)
}

\section{Ética e Serviço Social: fundamentos e contradições}

Resumo: Este ensaio tem o objetivo de problematizar a temática dos fundamentos éticos na sociedade contemporânea no que se refere ao reconhecimento de diferenças e à possibilidade de um efetivo exercício ético e político. Os argumentos partem da crítica que Marx faz ao caráter social do homem na sociedade capitalista e desenvolvem-se focados em três pontos: o primeiro, caracteriza o indivíduo na sociedade contemporânea, marcado pela incerteza, diversidade e diferença; o segundo, parte da compreensão de que esses aspectos exigem maior clareza nas inter-relações entre ética e política; e o terceiro, destaca diferentes concepções e expressões éticas da sociedade contemporânea. A construção desses argumentos exige um conhecimento rigoroso dos fundamentos éticos e políticos, sua diversidade e complexidade; elementos necessários ao debate da ética no Serviço Social.

Palavras-chave: Serviço Social. Ética. Política. Contemporaneidade.

\section{Ethics and Social Work: Fundaments and Contradictions}

Abstract: This essay analyzes the ethical fundaments in contemporary society and how they relate to the recognition of differences and the possibility for effective ethical and political exercise. The arguments are based on Marx's criticisms of the social character of man in capitalist society and focus on three issues. The first characterizes the individual in contemporary society, which is marked by uncertainty, diversity and difference. The second is based on the understanding that these factors demand greater understading of the interrelations between ethics and politics. The third highlights different ethical concepts and expressions found in contemporary society. The construction of these arguments requires a rigorous knowledge of ethical and political principles and their diversity and complexity; elements that are essential to the debate about ethics in Social Work.

Key words: Social Work. Ethics. Politics. Contemporary. 


\section{Introdução}

O ponto de partida desta reflexão é a concepção de que a ética e a política não integram a condição humana como expressão do desenvolvimento natural da espécie ou intrínseco à natureza humana. A posição tomada como referência afirma que o homem teve de perseguir a construção de seu próprio estatuto, fruto de sua autotransformação pelo trabalho, conquista marcada por contradições ao longo de sua trajetória histórica e social.

Encontramos esta fundamentação em Marx (2004, p. 106, 112): "O homem produz o homem, a si próprio e a outro homem [...]. O caráter social é o caráter universal de todo o movimento; assim como a sociedade mesma produz o 'homem' enquanto 'homem', assim ela é produzida por meio dele." Em seguida, afirma que "a natureza que vem a ser na história humana -no ato de surgimento da história humana é a natureza efetiva do homem [...]. A história mesma é uma parte efetiva da história natural, do devir da natureza até o homem."

Esta posição confirma a perspectiva e o objetivo deste texto: o de refletir e problematizar os fundamentos éticos e políticos para ampliar as possibilidades de compreensão de algumas contradições contemporâneas, a partir de três eixos:

a) a sociedade contemporânea está marcada pelo individualismo e apatia em que os valores parecem esgarçados e as causas que nos mobilizam, dispersas, gerando incertezas, diversidades e diferenças;

b) a ética e a política estão diretamente relacionadas à história e à sociabilidade humana, mas expressas por meio de diferentes concepções, condicionando as diferentes visões de mundo, nosso modo de pensar e agir, nosso modo de ser;

c) a coexistência de projetos distintos em permanente confronto faz reconhecer as diversidades, limites e contradições, que também se manifestam no Serviço Social.

Estas três indicações sinalizam que os diferentes modos de compreensão da sociedade implicam diretamente na formação ética e política dos indivíduos, em seus valores, seu pensar, agir e se organizar, isto é, forjam ideários, consolidam hábitos, comportamentos, um modo de ser. Ideários e sonhos que podem apontar para a construção de projetos coletivos e societários ou não acreditar nestes como possibilidade histórica, caracterizando diferenças e conflitos significativos na contemporaneidade.

Essas ponderações permitem afirmar que está implícito ao homem, em sua sociabilidade e historicidade, um exercício permanente de ação e reflexão, uma práxis, cujo entendimento tem aqui o sentido diferenciado de atividade prática. É compreendida como categoria central, pois vai além da interpretação das coi- sas e do mundo, é intenção e ação voltadas à transformação. A práxis é entendida não como mera atividade da consciência (embora seja esta elemento fundamental em uma sociedade em que o trabalho é alienado), mas sim como atividade material do homem social, que reconhece e pretende não apenas a interpretação de si e do mundo, mas também sua transformação (VÁZQUEZ, 1977).

Por isso, a questão da ética e da política torna-se problema real em nossas vidas, como expressão de nossa capacidade humana, cujas bases constitutivas são resultado de nossa práxis, mobilizada e mediada pelo trabalho. $\mathrm{O}$ trabalho entendido como mediação objetiva e efetiva da sociabilidade humana, e não de maneira reduzida como atividade produtiva capitalista (componente da atividade capitalista da produção), como uma lei natural. O que faz da reflexão ética e política um exercício de grande complexidade, pois propõe-se ampliar os horizontes históricos através de uma radical análise crítica para evitar reducionismos e ufanismos ${ }^{1}$, principalmente diante dos atuais paradoxos societários.

Destaque-se, neste sentido, a dialética entre forma e conteúdo, própria da modernidade, cujas possibilidades no uso da razão crítica não se esgotaram, mas tornaram-se expressões de ambiguidades, paradoxos e contradições, pois a modernização - como forma (industrialização, urbanização, organização do trabalho, desenvolvimento tecnológico etc) - é sempre bem-vinda para a afirmação do indivíduo e da propriedade. Entretanto, o fato de os indivíduos exigirem o seu espaço de arbítrio e criarem regras racionais e morais de convívio - conteúdo (racionalidade na economia, na política, na manifestação da democracia, no respeito aos direitos humanos e, em sua essência, no sentido da emancipação humana) -, choca-se com o próprio elemento dinâmico das sociedades contemporâneas (STEIN, 1997, p. 20). O princípio da contradição entre propriedade privada e trabalho criativo aparece como o maior obstáculo se o horizonte for a radicalização da democracia e a liberdade humana.

Estes são dilemas e paradoxos da sociedade contemporânea que expressam contradições e que, por isto, precisam ser conhecidos em seus fundamentos éticos e políticos.

\section{Sociedade contemporânea}

Expressões como sociedade, civilização e contemporaneidade são genéricas e muito difíceis de precisar conceitualmente. Nos dias de hoje, mais ainda, pois reconhecemos as particularidades históricas (com destaque ao plural) das diferentes sociedades e suas culturas, inclusive das várias civilizações que nos antecederam. 
Tendo como referência o pensamento marxiano, guiamo-nos pelo reconhecimento crítico do modo de produção capitalista que também é uma forma de reprodução da vida social, de construção de uma sociabilidade intermediada pela mercadoria, que tem por marcos a propriedade e a acumulação provenientes da expropriação da riqueza social produzida pelo trabalhador. Portanto, uma sociedade desigual e violenta.

A esta referência, contrapõe-se outra concepção de sociedade, em que civilizado é toda ação e todo comportamento que obedecem ao conjunto de regras, ideias e valores, referentes às práticas sociais dominantes, marcadamente as tradicionais, ou seja, tudo aquilo que gera hábito e controle, regulando as relações sociais e culturais. Esta condição foi muito bem descrita por Durkheim (1983, p. 92) ao explicar o fato social: "estamos, pois, em presença de modos de agir, de pensar e de sentir que apresentam a notável propriedade de existir fora das consciências individuais." Ao referir-se à coação como categoria central em seu pensamento, vai afirmar que a "estrutura política de uma sociedade é apenas a maneira como os diferentes segmentos que a compõem adquiriram o hábito de viver uns com os outros."

Esta simples citação indica um contraponto entre Durkheim e Marx e explicita um dos profundos debates da sociedade contemporânea. Na medida em que se reconhece (para Durkheim) que aquilo que pensamos acerca do mundo influencia o modo como vamos agir, definindo um claro sentido moral, este modo de pensar, no entanto, está (para Marx) diretamente determinado pela realidade material, pelo modo como se produzem e reproduzem as relações sociais e de produção, a constituição do próprio indivíduo social.

Apreende-se que não se tratam de simples diferenças interpretativas, são concepções de ética e política divergentes, porque carregadas dos valores que lhe dão forma e conteúdo nas maneiras de pensar e agir, de interagir consigo mesmo e com o mundo. Sua complexidade transparece nas escolhas que fazemos ao atribuir valores e significados a aspectos da vida cotidiana. Em uma concepção está a valorização da coerção como elemento moral fundamental para a coesão social. Em outra, a determinação material das relações sociais, como limite à consciência de sua condição humana, como possibilidade de transformação destas relações.

A nosso ver, estas diferentes concepções éticas e políticas, que fundam o pensamento social na modernidade, são atravessadas por outros fatores próprios da sociedade contemporânea. Dessas contradições, sinalizamos três, que consideramos relevantes: a diversidade, o conflito, e a incerteza.

Se a sociedade contemporânea aparenta permitir cada vez mais a expressão e o reconhecimento das diferenças e da diversidade como condição existencial do homem contemporâneo, ela é reduzida, muitas vezes, a um relativismo danoso, pois tende a uma "aglutinação cultural", que fragmenta o sujeito, ou seja, o agente ético e político "como um ser racional e consciente que sabe o que faz, como um ser livre que decide e escolhe o que faz e como um ser responsável que responde pelo que faz" (CHAUÍ, 1999, p. 5).

O surgimento e a expansão de diferentes áreas do conhecimento como resposta às demandas emergentes não implicam, necessariamente, na formação de uma nova condição humana, ou em um sentido para além de si mesma. É neste ponto que a diversidade, muitas vezes, se reduz ao conflito. A impossibilidade de reconhecer o outro (sujeito, área de conhecimento, instituição etc), diante de uma fragmentação que se impõe como realidade única e suficiente, desqualifica o diálogo crítico, não há mais a quem se reportar senão a si mesmo, "[...] o que nos resta é o conflito que, por sua vez, se diversifica conforme as circunstâncias. A princípio, pode parecer uma questão contingencial, mas, no fundo, é existencial também" (NUNES, 2009, p. 30)².

Com este enfoque de análise, diversidade e conflito em uma sociedade massificada, o individualismo e a apatia são exacerbados e os valores utópicos que davam sentido às lutas parecem esgarçados, as causas que sempre mobilizaram lutas coletivas tendem a se dispersar, evidenciando a incerteza como condição do homem contemporâneo. É fortalecida a sensação de crise, individual ou societária, seja de valores, de pensamentos, divulgando uma concepção pessimista e catastrófica. Vale pensar, em outro caminho, um perfil de crise que não o de multiplicador de carências e negações, mas um perfil propriamente ativo, que se sobreponha à passividade de todo processo, à ação do pensamento crítico (NUNES, 1994, introd.).

O homem desta sociedade contemporânea está condicionado, também, pela distopia (do grego "lugar mal" diferente de utopia "lugar nenhum"), na qual romance, ficção, ciência e realidade interagem contraditoriamente, confundem-se e apontam para 
uma tendência política e social catastrófica. Os limites societários são extrapolados, e as fronteiras entre o absurdo e a realidade deixam de ser percebidas, criando uma situação anômala e congênita, uma vida de incertezas.

Um exemplo marcante desta incerteza aconteceu em 6 de agosto de 1945, com a experiência do genshi bakudan ${ }^{3}$, desde então, como civilização, não somos mais os mesmos. Pode-se acrescentar a isto nossa experiência cotidiana, diante das imagens ao vivo que as mídias disponibilizam. Um cenário de espetáculos e tragédias reais, que nos aproxima a tal ponto de confundirmos os sentimentos humanitários, despertados pela sensibilidade, para banalizarmos as situações, como espetáculo de consumo. Em ambas as situações, o medo penetra em nossos lares, reduzindo as possibilidades de uma razão crítica que liberte, que vislumbre possibilidades.

Esta expressão do contemporâneo reforça nossa clausura espacial e temporal, e intensifica o isolamento, bases para o individualismo. A violência se sobrepõe à ética que reduz a opção política, enquanto possibilidade de participar da construção daquilo que consideramos bem público, a liberdade e a justiça social (BUORO, 1999, p. 44). Esta condição societária faz da ética e da política discurso recorrente, contingência e necessidade existencial.

\section{Ética e política}

O retrato societário apresentado não é uma reflexão fatalista sobre uma humanidade sem alternativas e esperanças. É, antes, o exercício da crítica para buscarmos outras necessidades, condição reconhecida a nos indicar e valorar o custo humanitário de nossas conquistas, que tendem a favorecer a apatia, e a perda de sentido da potencialidade humana. Marx (2004, p. 141) indica-nos este caminho ao falar do economista (enquanto capitalista e modo de existência científico) que argumenta sobre a privação de necessidades, diz ele:

[...] na medida em que ele reduz a carência do trabalhador à mais necessária e mais miserável subsistência da vida física e sua atividade ao movimento mecânico mais abstrato; ele diz, portanto: o homem não tem nenhuma outra carência, nem de atividade, nem de fruição; pois ele proclama também esta vida como vida e existência humanas; [...]. Por isso, ela é - apesar de seu aspecto mundano e voluptuoso uma ciência efetivamente moral, a mais moral de todas as ciências.

É esta contradição que nos indica a possibilidade da escolha humana, do exercício da crítica e da capacidade histórica do homem indignar-se com o atual estado das coisas, com os rumos societários, com a própria vida, não abrindo mão de sua possibilidade e condição de sujeito histórico - campo da ética e da política.

Do ponto de vista conceitual, a ética é aqui compreendida como a crítica fundamentada da moralidade humana, e não um dever a ser cumprido. Compreensão que vem perdendo este fundamento crítico. A cada dia, o apelo ético, quanto mais falado e pronunciado, mais banalizado fica, permitindo usos e abusos. Todavia, esta banalização, favorece a despolitização da ética, a perda de sua criticidade. No dizer de Romano (2001, p. 94),

[...] de um lado, notamos o uso sem peias de uma forma complexa de pensamento, uma das mais difíceis dentre as produzidas pelo saber filosófico. De outro, presenciamos, nos discursos dirigidos ao público, a negação da moral como fundamento da sociedade e da vida política. [...] para usar a metáfora do mercado, a de Marx, as doutrinas filosóficas sobre a ética perdem a sua qualidade de origem e na concorrência desenfreada transformam-se em produtos de pacotilha.

Nisto está a relevância, pois a proposta não é a moralização da política, sua subordinação à moral, e sim, o contrário, a sua desmoralização, retirar da política os moralismos que controlam a autonomia, subordinam a participação e restringem a democracia.

A referência indicada é a construção democrática, e para isto seguimos as reflexões de Coutinho (2006, p. 26), ao afirmar a necessária soberania e participação de todos, ou seja, a socialização da política e do poder. Se todos são cidadãos, isto quer dizer que todos podem e devem participar na formação do poder:

[...] com isso, estou querendo dizer que a democracia - se a entendermos no sentido forte da palavra, isto é, no sentido da igualdade material, da participação coletiva de todos na apropriação dos bens coletivamente criados etc. - tem também uma dimensão social e econômica. Não há efetiva igualdade política se não há igualdade substantiva, uma igualdade que passa, necessariamente pela esfera econômica.

Portanto, a relação entre ética e política é imbricada, mediada pelo poder em sua disputa pela liberdade e, nesta concepção, fundada na igualdade substantiva. Este é o ponto central da interseção entre ética e política, pois não basta um dever, exige-se também um querer. É preciso saber o que se quer, e ainda, se este é realmente fator de preservação do estado de coisas ou de sua transformação. Tem-se então que a crítica é também análise, que o indivíduo não é sujeito isolado, mas sujeito ético estruturalmente situado na sociedade, ca- 
paz de fazer opções e tomar decisões, fazer-se político em seu próprio exercício como homem.

A compreensão teórica desta relação entre ética e política e sua necessária vinculação à realidade social indica-nos uma tendência expressiva deste novo século 21. A de um desconforto político com tantas desigualdades sociais, as incongruências e os abusos do poder político e econômico, as diferentes formas de violência.

Esta insatisfação com os rumos da política ampliou as preocupações em torno da ética, fazendo com que ambas (ética e política) sejam retomadas com grande intensidade e diversidade de abordagens. Esta retomada é evidenciada, na maioria das vezes, pela mídia, tanto na crítica moralista (já comentamos a moralização da política), como também na moral individual e egoísta, indicando a urgência de atitudes e respostas, sem preocupações com os fundamentos éticos ou sentido das ações. Esta direção recoloca o papel dos indivíduos e, por que não, das profissões e organizações na sociedade, sobretudos as privadas, como um exercício qualificado que precisa responder às demandas para promoção da cidadania, da responsabilidade social, do voluntariado (KAMEYAMA, 2004).

Na sociedade contemporânea desigual e violenta, onde as distâncias sociais e econômicas são escancaradas a cada esquina, há um apelo ao social, que se transforma em discurso ético. Estão dadas as condições para um aparato cultural e institucional importante para o desenvolvimento da economia capitalista. A necessidade e o desejo individual de "fazer alguma coisa", seja para o próximo, ou seja, para "salvar a própria pele", tornaram-se um grande negócio, um tipo peculiar de economia.

$\mathrm{O}$ marketing, mobilizador de interesses para o mercado, respondeu a esta demanda social e política, atenuando a ênfase econômica da produção para a distribuição, e enaltecendo o consumo. Ao mesmo tempo, esta relação de distribuição e consumo, enquanto responsabilidade social, ética e política dos indivíduos, foi subordinada às instituições dominantes da economia capitalista, canalizada pelas grandes corporações, empresas privadas e bolsas de valores. O sociólogo norte-americano Wright Mills (2009, p. 74) sintetiza muito bem isto:

Nesse vasto mecanismo de merchandising de anúncios e design, não há nenhum objetivo social inerente para equilibrar seu grande poder social; não há nenhuma responsabilidade incorporada para ninguém, exceto para o homem que aufere o lucro. Há pouca dúvida, contudo, de que esse mecanismo é hoje um importante definidor dos valores e padrões da sociedade [...], o principal portador da sensibilidade cultural [...]. Esse aparato é hoje um auxiliar de organizações comerciais que usam a cultura para seus próprios fins não cultu- rais - de fato, anticulturais -, e assim degradam seu próprio significado. Esses usos da cultura estão sendo moldados por homens que transformariam todos os objetos e as qualidades, de fato a própria sensibilidade humana, num fluxo de mercadorias efêmeras [...].

O que é evidenciado, todavia, por Kameyama, (2004, p. 156):

[...] longe de ser fruto de algum altruísmo empresarial das empresas capitalistas, resulta de um processo político de pressões exercidas por contrapartes organizadas. Mas também, curiosamente, ao arrefecer os ânimos das entidades da sociedade civil que demandam a implementação de políticas sociais universais, as empresas passam a investir em projetos comunitários, em pesquisa e desenvolvimento, em programas de qualificação de seus funcionários, em umas tantas políticas que se confundem com estratégias de marketing e que acabam dando retorno financeiro.

Percebe-se que a questão ética e política, contraditoriamente marcada pela moral individualista e egoísta, de derivação emotiva ou da consciência íntima da esfera particular de cada indivíduo, agora evidencia um discurso e prática da responsabilidade social. Ao mesmo tempo, a sociedade civil reivindica o respeito e a responsabilidade públicos e privados, colocando este discurso em cheque, onde a garantia de direitos exige ações firmes, contrárias às desigualdades e violências.

É nesta direção que o filósofo Hans Jonas (1995, p. 16, tradução livre) fala da responsabilidade, no sentido de responder as consequências (tecnológicas) e indicar possibilidades (utopias), afirmando que:

Não se trata de um fenômeno novo para a moralidade, não obstante a responsabilidade, nunca antes teve consideração como objeto e, até agora, havia ocupado pouco a teoria ética. [...] Tanto o saber como o poder eram demasiados limitados para incluir a consciência da própria causalidade do globo terrestre. [...] Com o avanço da tecnologia, a ética tem a ver com as ações - não mais do sujeito individual - de um alcance causal sem precedentes e que afeta o futuro. [...] A ampliada dimensão de futuro da responsabilidade atual nos conduz ao tema final: a utopia.

Diante destas adversidades da sociedade contemporânea, o apelo pela ética é também uma retomada da responsabilidade sobre nossas vidas. A ética, ao ser retomada, assume o significado do questionamento diante do que é a realidade, e, também, do que deveria ser em nossa vida cotidiana. Uma vida cotidiana 
na qual a escolha moral é tomada de decisão, poder e conflito, isto é, política.

Isto nem sempre foi assim concebido. Durante um longo tempo, a moral dominou a vida social e política através da religião, estabelecendo critérios normativos para os indivíduos e instituições. E desde o século 15, com a racionalização e a secularização, criou-se uma razão instrumental que não discutia a moralidade dos objetivos. O próprio Estado em sua formação tornavase a salvaguarda do poder por meio da qual a ética dos fins era transformada em uma ética dos meios.

Na modernidade, as questões políticas tornaramse econômicas, Estado e sociedade civil politizaram sua relação e estabeleceram princípios éticos para a vida pública e privada. Com o capitalismo contemporâneo, a coisa pública tornou-se um grande negócio privado, dos indivíduos aos grandes grupos financeiros. A exacerbada manifestação do interesse individual e privado desta sociedade sobrepõe-se à unicidade entre ética, política e economia, desqualificando a relação entre meios e fins.

Nossa compreensão vai em sentido contrário; pela nossa reflexão, apesar de estarem intimamente vinculadas, a crise da política é também uma crise ética e também uma crise econômica. É este o sentido que atribuímos quando afirmamos que no centro da relação entre ética e política estão a igualdade substantiva e a liberdade.

Percebe-se, então, o quanto os mecanismos contemporâneos fragilizam o próprio homem, na medida em que a tentativa de desvincular ética e política, ou de moralizar a política, são frutos de uma sociedade que construiu as maiores possibilidades científicas e tecnológicas da humanidade. E sobre as quais não tem efetividade, pois há um descompasso, que leva ao embrutecimento e à desumanização, reduzindo as potencialidades humanas, a igualdade e a liberdade.

A liberdade não é apenas ausência de constrangimentos ou de limites, muito menos de desconsideração da realidade. Ela é um profundo e dramático compromisso consigo mesmo e com os outros, com as questões políticas, econômicas e sociais. É uma resposta ao desafio de restringir limites e de ampliar as possibilidades de ação de todos os homens. E a dificuldade e a beleza desta busca, o fazer-se e o saberse da humanidade, onde o faber e o sapiens são elementos de nós mesmos.

Isto para afirmar que a liberdade resulta de um projeto de ação - com o risco de descaminhos, se sufocado à revelia dos sujeitos ou se eles dela abdicam, por comodismo, medo, ou insegurança, adotando a servidão voluntária. É La Boetié, filósofo do século 16, citado por Chauí (1994, p. 406), quem explica que desejamos a tirania, quando nos fixamos no desejo de ter, de posse, desprezando a liberdade, aceitando a servidão voluntária:
[...] não sendo obrigados a obedecer ao tirano e aos seus representantes, mas desejamos voluntariamente servi-los porque deles esperamos bens e a garantia de nossas posses. Usamos nossa liberdade para nos tornarmos servos. [...] Se não trocarmos nossa consciência pela posse de bens e se não trocarmos nossa liberdade pelo desejo de mando, nada daremos ao tirano e, sem poder, ele cairá como um ídolo de barro.

No sentido oposto a esta condição, está o reconhecimento de que somos seres inacabados, e o grande desafio é a construção desse ser social, de sua liberdade. A experiência de sua construção transpassa: indignação ética, como desmascaramento do mundo; diferença, como possibilidade de negar as verdades absolutas; conflitos, pois nem tudo é programado e definido, existem as intenções e suas consequências.

A liberdade, enquanto exigência do ato moral, não é mera ausência de limites, de desconsideração da situação. Pelo contrário, representa sempre uma resposta ao desafio de restringir esses limites e de ampliar as possibilidades de ação de todos os homens.

\section{Fundamentos e contradições}

O reconhecimento dos limites e das contradições entre ética e política e o esforço coletivo de luta pela liberdade leva-nos a buscar alguns fundamentos que estão, aparentemente, distantes destas questões, mas que, no entanto, examinados com atenção, mostramse quão significativos são para a formação de nossas convicções e valores morais.

Embora as discussões em torno da ética e da política remontem à Grécia antiga, neste trabalho, é a modernidade, o campo por excelência destas questões, representado, particularmente, por dois grandes pensadores ${ }^{4}$.

O primeiro, é Immanuel Kant (1724-1804) que desviou o pensamento filosófico das investigações metafísicas sobre as causas e o ser para concentrá-lo na análise reflexiva das condições que possibilitam o conhecimento e garantem a sua objetividade. É a filosofia transcendental, que utiliza a análise reflexiva do conhecimento científico, em que as categorias, depuradas de qualquer conteúdo psicológico ou metafísico, exercem o papel de princípios lógicos e metodológicos, os quais se aplicam à diversidade dos fenômenos no espaço e no tempo.

Sua filosofia está fundada na obrigação moral única e geral, que explica todas as outras obrigações morais, por meio do "imperativo categórico" que é o dever de toda pessoa de agir conforme os princípios que ela quer que todos os seres humanos sigam, tal qual uma lei da natureza humana. O imperativo categórico de Kant é "age de tal modo que a máxima da tua 
ação se possa tornar princípio de uma legislação universal". É uma obrigação individual que temos independentemente da nossa vontade ou desejos. O homem como ser natural está submetido a leis de causa e efeito, mas, na crítica da razão prática, a liberdade é o postulado da ordem moral fundada no "dever ser" (juízos de valor são o núcleo de toda experiência e é a eles que estão vinculados todos os ideais da razão).

Para Kant, o homem cognoscente é também moral, é a mais alta manifestação de humanidade, pois é um ser ativo, criador e legislador, tornando-se responsável pelos seus atos. E, diante da liberdade de criar normas morais e fins éticos para si mesmo, tem o dever de cumpri-las, obedecer a elas é obedecer a si mesmo, é ser autônomo, é impor o dever moral sobre nossas tendências naturais para sermos livres.

O segundo filósofo é Hegel (1770-1831) que faz crítica a Kant, sustentando o descobrimento simultâneo do pensamento e da realidade, a evolução da natureza e do espírito e o caráter histórico do pensamento, da filosofia e da cultura. A conexão orgânica, que varia, conforme mudam as condições do desenvolvimento humano, entre arte, religião e ciência.

Hegel faz uma dura crítica à atenção dada por Kant à relação sujeito humano e natureza, desqualificando a relação do homem com a cultura e a história. Critica, também, a visão centrada no sujeito autônomo, cuja sociabilidade apoia-se em suas relações pessoais e diretas com outros indivíduos e não a partir das relações sociais, das instituições sociais, pois, segundo Hegel, são estas que determinam a vida ética ou moral. É esta a visão que se ampliou com este filósofo: de um aspecto subjetivo do sujeito moral para uma concepção objetiva, dada pelas instituições, pela história e pela cultura.

Desta forma, são as relações sociais que determinam a vida ética, resultando a interação entre a vontade subjetiva individual e a vontade objetiva cultural, interiorizando nossas relações a ponto de tornarem-se espontâneas e serem praticadas livremente (costumes, valores), como nossa vontade e nossos desejos, nosso dever. No entanto, deixam de ser universais no sentido do imperativo categórico de Kant, pois para Hegel, cada sociedade e cada cultura, historicamente, definirão conteúdos e valores de sua época, até entrarem em declínio e surgirem outros.

$\mathrm{Na}$ tradição filosófica, para toda fundamentação argumentativa, há sempre uma contraposição rigorosa e, neste campo do esforço de construir uma razão explicativa do homem e de sua natureza, capaz de compreendê-lo em sua totalidade, desenvolveu-se uma reação, por entender que este esforço (em Kant e Hegel) foi puro idealismo.

Esta reação ao idealismo em Kant e Hegel foi sustentada por duas escolas que se organizaram em fins do século 19. A primeira, o Realismo, em oposição ao Romantismo, parte do pressuposto que a avaliação do conhecimento e a evolução da consciência são um mesmo processo de síntese de atividade do pensamento com a experiência das coisas, sendo desta que nasce a ciência. Sua posição está demarcada pelo desprezo à imaginação romântica, priorizando a descrição da realidade, acentuando os aspectos negativos da natureza humana.

A segunda, o Pragmatismo, originária dos Estados Unidos, leva em conta a experiência positiva do revolver da cultura pela técnica e pela indústria, cujos efeitos se fazem sentir na vida humana e na sociedade, postura de oposição frontal à tradição especulativa do ideal cartesiano como conhecimento fundamental. A centralidade de seu pensamento está por considerar o valor das ideias a partir de sua utilidade, ou melhor, de seus efeitos práticos e valor funcional. $\mathrm{O}$ Pragmatismo constituiu-se como uma crítica à metafísica. Neste sentido, a razão é subordinada àquilo que motiva e justifica a ação, que tem consequências práticas. O conhecimento não é o primeiro nexo que nos une à realidade, portanto, o real é o que convém ao desenvolvimento da nossa eticidade e está de acordo com os seus fins.

Este debate vai trazer um novo ponto a ser discutido no campo da ética que é o da existência individual, a vertente existencialista, particularmente as ideias de Kierkegaard (1813-1855) e Heidegger (1889-1976). O homem é desejo, inquietude e sofrimento, uma consciência infeliz, vivendo mais do desejo que da satisfação, por isto a angústia e o desespero, onde a individualidade não pode se explicada.

A base desse pensamento está focada na interpretação do ser, nos modos e nas maneiras como se expressa e no sentido que este ser constrói para si. O foco do Existencialismo é o sentido de Ser, seus modos e maneiras de expressão, que são realidade concreta, levando à compreensão de que cada homem é um ser único, sujeito que decide sobre seus atos e seu destino, cria seus valores e suas escolhas. A ética, nesta perspectiva do Existencialismo, está centrada na liberdade como única fonte de valor das escolhas, considerando cada homem como um ser único, responsável por suas escolhas e seu destino.

O reconhecimento do sujeito individual favorece o surgimento de outro pensamento, de acordo com o método psicanalítico de Freud (1856-1939), que vai refletir sobre o conflito irremediável entre as leis sociais e os desejos individuais, gerando um inevitável e infindável conflito ético. Ao trazer o conceito de inconsciente, limitando o poder da razão e da consciência, também trouxe uma nova compreensão da sexualidade como força pulsante de nossa existência. Por esta perspectiva, somos resultado de nossa própria história de vida, de repressões a uma sexualidade insatisfeita, que busca sua satisfação e prazer, mas que não pode satisfazer-se plenamente. $\mathrm{O}$ esforço para 
explicar racionalmente a lógica do inconsciente é reconhecer que ele é ativo e dinâmico. Isto porque a natureza do inconsciente é sexual, a libido e sua repressão causam distúrbios e neuroses, ou seja, a ética não pode ignorar esta motivação e, por isto, deve mostrar que é imoral julgar como moral os atos que obedecem a forças inconscientes irresistíveis.

Nesta direção da crítica ao idealismo e a metafísica, problematizando os valores e o racionalismo ético, foi o pensamento de Nietzsche (1844-1900), um crítico do cristianismo e do socialismo, que construiu uma visão trágica do mundo. Suas ideias partem do primado das forças inconscientes e instintuais, que são as forças vitais que formam o núcleo afetivo e irracional da realidade, decorre daí a natureza trágica da vida, pois são elas que se afirmam nos indivíduos para impulsioná-los à destruição. A vida é instinto e instinto é poder, a vontade de poder. Este pensamento fortalece uma extrema individualidade, uma desagregação final, o eterno retorno e a vontade de poder, que é o impulso e o instinto natural. O destino deste indivíduo é de possibilidades ilimitadas, mas está dependente destas funções e a elas se subordinam a consciência, a moral, a razão e a lógica, é a vertente irracionalista. Esta concepção contesta o poder da razão e sua capacidade de intervir sobre os desejos e as paixões.

A autoformação do homem é irracionalista, pois a razão deriva da vida. A razão é um poder eficaz, mas secundário, e que via de regra interfere de maneira negativa no processo de autoformação do homem. A desnaturalização do homem foi a domesticação, levando a uma decadência da cultura, ao niilismo, a uma crítica demolidora dos valores.

Seu marco está definido pela não conformidade com a razão apriorística, cartesiana, sustentada por uma concepção subjetiva de fundo individualista da experiência do homem. Convém destacar que o irracional pode ser o teor social, coletivo e impessoal da experiência, é o lugar filosófico que certas realidades têm e que são irredutíveis ao pensamento analítico. O irracionalismo, talvez seja o nome provisório de uma nova razão, é uma razão operante que se constrói com a experiência, construindo seu objeto, para além de uma razão controladora e opressora, por meio de uma nova ética que liberte do desejo da repressão que a própria sociedade construiu.

Estas vertentes vão trazer impactos profundos sobre os fundamentos éticos e, de certa forma, vão impregnar o pensamento contemporâneo. Em particular, abrem um debate profundo entre a existência social e a existência individual, entre o racionalismo e o irracionalismo.

Neste ponto, irrompe a compreensão pautada na tradição crítica (Marx, 1818-1883) de que a existência individual implica a existência social, ou seja, os acontecimentos históricos, as lutas políticas e sociais. Ao satisfazerem suas necessidades fundamentais, os homens, conforme o grau de domínio alcançado sobre a natureza, contraem determinadas relações objetivas, que se situam acima dos indivíduos e que independem da sua vontade. São as relações de poder entre as classes, o significado econômico e social e a possibilidade de construção histórica.

A possibilidade da construção humana da história exige retomar o conceito de moral, derivado do latim mores, que significa costumes ou os modos de agir de uma sociedade, anteriores ao nosso nascimento, considerados como valores e obrigações, criação cultural e humana. A moral, os costumes, os deveres e as obrigações são sustentados por valores, definidos na experiência cotidiana de instituições e organizações sociais concretas, através das quais se estruturam relações de poder, definidas e assimiladas pelos indivíduos socialmente determinados. Quase sempre internalizadas não por autonomia das próprias convicções, mas pelo consenso, pela coerção ou pela imposição social.

Por isto, quando evidenciamos a razão crítica como critério de deliberação e escolhas, é porque identificamos a moral como um sistema de normas, princípios e valores que são determinados histórica e socialmente, e que passam a definir as relações entre os indivíduos e destes para com a sociedade, de tal modo que essas normas tornam-se aceitas livre e conscientemente, e não necessariamente de modo coagido e imposto. A moral é interiorizada como ato volitivo que exige convicções próprias, através das quais julga e avalia a consciência e as imposições que a sociedade coloca. Portanto, a moral passa pela subjetividade, mas é concreta e objetiva, compreensível a partir do leque de relações sociais que o ato humano constrói e reconstrói historicamente, no dizer de Pereira (1991, p. 11) "é tudo aquilo (ato, comportamento, fato, acontecimento) que realiza o homem, que o enraiza em si mesmo e, por ele e para ele, ganha sentido humano."

É isto que faz da ética um problema real de nossas vidas, cujo entendimento está pautado em uma perspectiva histórica, como busca dos fundamentos do comportamento moral do homem, que implica tanto a reflexão radical e crítica, como a ação política.

Nesta perspectiva, a ética não surge de princípios apriorísticos, fixos e imutáveis, de valores universais e perenes, mas da própria consciência histórica do homem que percebe a si mesmo nas condições e relações que estabelece com os outros, com a sociedade e com a natureza. Assim, a ética não pode ser concebida como algo além da vida social e histórica. É expressão da consciência que os homens têm de si, enquanto indivíduos sociais, ou seja, de sua própria ação humana, enquanto seres sociais. Segundo Marx, (2004, p. 107):

Acima de tudo é preciso evitar fixar mais uma vez a 'sociedade' como abstração frente ao indivíduo. 
O indivíduo é o ser social. Sua manifestação de vida - mesmo que ela também não apareça na forma imediata de uma manifestação comunitária de vida, realizada simultaneamente com outros -é, por isso, uma externação e confirmação da vida social. A vida individual e a vida genérica do homem não são diversas, por mais que também - e isto necessariamente - o modo de existência da vida individual seja um modo mais particular ou mais universal da vida genérica, ou quanto mais a vida genérica seja uma vida individual mais particular ou universal.

Portanto, a ética é sempre uma construção histórica humana, pois

[...] o homem - por mais que seja, por isso, um indivíduo particular, e precisamente sua particularidade faz dele um indivíduo e uma coletividade efetivo-individual - é, do mesmo modo, tanto a totalidade, a totalidade ideal, a existência subjetiva da sociedade pensada e sentida para si, assim como ele também é, na efetividade, tanto como intuição e fruição efetiva da existência social, quanto como uma totalidade de externação humana de vida. Pensar e ser são, portanto, certamente diferentes, mas [estão] ao mesmo tempo em unidade mútua.

Então, se a ética é uma construção histórica humana, ela precisa ser concebida a partir de uma crítica radical do trabalho, como autocriação humana, que não se realiza plenamente na sociedade capitalista. Pois, nesta, o homem é obrigado a vender a outros homens sua força de trabalho, a autocriação humana não chega a se realizar, pois o homem não se reconhece no produto de seu trabalho, um trabalho alienado.

Para Marx, não há uma moral a ser estabelecida, mas a exigência de uma nova ética que se dá, precisamente, pela libertação do homem, tornado consciente de si mesmo como ser social, como processo de libertação do trabalho alienado. Assim, em Marx, ética e trabalho encontram-se em íntima relação, isto é, não pode haver ética enquanto o homem concreto, o homem real, estiver alienado em sua própria essência que é o trabalho (VARES, 1989, p. 63).

Se considerarmos os valores propostos no mundo capitalista, como a democracia, a liberdade, a felicidade, veremos que são hipócritas, porque irrealizáveis em uma sociedade repressora e violenta, baseada na exploração do trabalho, na desigualdade social e econômica, sem garantia dos direitos sociais e políticos.

A ética, a partir do pensamento de Marx, é uma crítica da moral existente, que emerge da própria consciência que percebe a condição de objeto (reificação) ou de estranheidade (alienação) do homem diante de seus próprios produtos (VARES, 1989, p. 65).
A ética, neste sentido, compreende o exercício da crítica permanente a todas as formas de exploração, exclusão e discriminação do homem diante da liberdade. Sendo a liberdade a possibilidade de construção histórica de valores que se efetivam na sociabilidade do homem.

\section{Notas ao debate dos fundamentos éticos no Serviço Social}

Já é significativa a literatura existente no Serviço Social sobre os seus fundamentos éticos, com destaque para Bonetti (1996), Barroco (2001) e Forti (2009), como também sobre o projeto ético-político da profissão, onde se destacam Iamamoto (1998), Paulo Netto (1999) e Teixeira e Braz, (2009).

Tendo estas referências como ponto de partida, cabe reconhecer que o projeto ético-político profissional do Serviço Social é fato. Como a própria expressão indica, articula a ética e a política e constitui marco histórico de referência à sua organização profissional e, por isto mesmo, é, também, um movimento de intenções e ações, que apontam uma direção social, que precisa ser plural e democrática para reproduzirse. E, portanto, e por isto mesmo, diverso e contraditório, ${ }^{5}$ tal qual a sociedade da qual faz parte.

Foi por este motivo que indicamos, no início do texto, a práxis como ponto de articulação entre a ética e a política. Pois, pensar o projeto ético-político é compreendê-lo no seio de uma práxis, como movimento do pensamento e da ação, voltados à transformação. Cabe destacar que isto não é garantia de sua realização, é apenas possibilidade, ou seja, exercício constante de busca, uma luta cotidiana difícil e complexa diante das contradições e dos paradoxos societários existentes.

A compreensão do projeto ético-político profissional do Serviço Social pressupõe a percepção da processualidade e da historicidade da própria profissão, suas respostas às necessidades e às demandas societárias enquanto sujeito coletivo e seus vínculos teórico-práticos, éticos e políticos com os projetos societários, seus fundamentos e sua direção social, mas não pode confundir-se e igualar-se a estes.

É neste ponto, ou melhor, nesta convergência, que reconhecemos a coexistência de projetos distintos em permanente confronto, inegável condição de diversidades, diferenças e conflitos, problemática para a qual apresentamos, inseridas a este contexto, algumas notas para reflexão.

- A compreensão da sociedade capitalista, a partir de uma perspectiva histórica e de totalidade, é condição para apreensão de suas contradições, nuances e contornos que projetam uma complexidade ética e política que não pode 
ser reduzida ou menosprezada, como se tudo já estivesse suficientemente explicado.

- A complexidade, a qual nos referimos, consiste em levar em conta as incertezas, diversidades e diferenças existentes na sociedade contemporânea que afetam e são afetadas por nossas concepções de ética e política.

- A fragmentação que marca a sociedade contemporânea e suas condições, resultam de diversidade e diferenças que, muitas vezes, reduzem-se ao conflito e ao medo. Até que ponto a luta pela hegemonia que se trava na profissão implica o reconhecimento dessas condições que recaem sobre o sujeito profissional e qual sua penetração nas diferentes concepções existentes, suas nuances e perspectivas no cotidiano?

- A diversidade e a diferença não representam apenas o lado negativo de uma sociedade que luta pela sua sobrevivência e reprodução, mas, também, o reconhecimento de uma face positiva, que nega as iniquidades estabelecidas e luta pela justiça, igualdade e liberdade.

- A compreensão da luta ética e política que se trava como esforço único para "aniquilar as forças inimigas", é reprodução de uma condição de pensamento e ação, típicos de uma ética universalista e moralista.

- O risco de uma idealização política, homogênea, quase pura, que reduza a diversidade, é não contemplar a complexidade contemporânea, recaindo em formas tão tradicionais quanto qualquer autoritarismo, inclusive na própria profissão.

- A capacidade de realizações, atribuída à crença de que os valores vão formar uma consciência diferenciada, sem alterar antecipadamente as condições materiais de produção e reprodução das relações sociais, refere-se a retomar o idealismo e o conservadorismo que se abrigam no Serviço Social.

- A diversidade de concepções das vertentes éticas e políticas, sinteticamente apresentadas em seus fundamentos, não podem ser simplificadas, como se fossem todas semelhantes, sem qualidades, e, muito menos, ignoradas.

Não acreditamos que se faça um projeto éticopolítico profissional sem o reconhecimento claro e profundo das diferenças existentes. Julgamos que esteja no esforço da compreensão radical (a raiz) de seus fundamentos e da possibilidade de aprender a conviver com as diversidades, o caminho para o exercício ético e político diferenciado.

Neste ensaio, demos ênfase às citações de Marx, particularmente dos Manuscritos econômico-filosóficos, texto importante de sua juventude, não apenas por fazer a transição entre o idealismo hegeliano e a concepção materialista em sua trajetória, mas por de- senvolver uma explicação crítica muito clara da ética e da política no capitalismo. Assim, buscamos neste autor uma reflexão que se aplica ao tema aqui desenvolvido. Ao tratar do dinheiro, por intermédio do qual se consegue tudo o que o coração humano deseja, sou possuidor de todas as capacidades humanas? A esta questão formulada por Marx, acrescentamos: meu dinheiro, meus desejos, meus ideais e minha vontade moral não podem transformar, todas as minhas incapacidades no seu contrário?

\begin{abstract}
Pressupondo o 'homem' enquanto 'homem' e seu comportamento com o mundo enquanto um [comportamento] humano, tu só podes trocar amor por amor, confiança por confiança etc. Se tu quiseres fruir da arte, tens de ser uma pessoa artisticamente cultivada; se queres exercer influência sobre outros seres humanos, tu tens de ser um ser humano que atue efetivamente sobre os outros de modo estimulante e encorajador. Cada uma das tuas relações com o homem e com a natureza tem de ser uma 'externação determinada' de tua vida 'individual efetiva' correspondente ao objeto da tua vontade. Se tu amas sem despertar amor recíproco, isto é, se teu amar, enquanto amar, não produz o amor recíproco, se mediante tua 'externação de vida' como homem amante não te tornas 'homem amado', então teu amor é impotente, é uma infelicidade (MARX, 2004, p. 161).
\end{abstract}

\section{Referências}

BARROCO, M. L. Ética e Serviço Social: fundamentos ontológicos. São Paulo: Cortez, 2001.

BERLINGUER, G. Questões de vida: ética, ciência e saúde. São Paulo: Hucitec, 1993.

Bioética cotidiana. Brasília: Ed. UnB, 2004.

BONETTI, D. et al. Serviço Social e ética: convite a uma nova práxis. São Paulo: Cortez, 1996.

BUORO, A. et al. Violência urbana: dilemas e desafios. São Paulo: Atual, 1999.

CAMPS, V. Historia de la ética. Barcelona: Editorial Crítica, 1989. (v. 3).

CHAUÍ, M. Convite à filosofia. São Paulo: Ática, 1994.

Uma ideologia perversa. Folha de São Paulo, São Paulo, 14 mar., 1999. Caderno 3, p. 5.

CORTINA, A. Cidadãos do mundo: para uma teoria da cidadania. São Paulo: Loyola, 2005. 
COUTINHO, C. N. Intervenções: o marxismo na batalha das ideias. São Paulo: Cortez, 2006.

DURKHEIM, E. As regras do método sociológico. São Paulo: Abril Cultural, 1983. (Coleção Os Pensadores).

FORTI, V. Ética, crime e loucura: reflexões sobre a dimensão ética no trabalho profissional. Rio de Janeiro: Lumen Juris, 2009.

HARVEY, D. Condição Pós-Moderna. Tradução de Adail Ubirajara Sobral e Maria Stela Gonçalves. São Paulo: Loyola, 1996.

HERSEY, J. Hiroshima. Tradução de Hildegard Feist. São Paulo: Cia das Letras, 2002.

IAMAMOTO, M. V. O Serviço Social na contemporaneidade: trabalho e formação profissional. São Paulo: Cortez, 1998.

JONAS, H. El principio de responsabilidad: ensayo de uma ética para la civilización tecnológica. Barcelona: Editorial Herder, 1995.

KAMEYAMA, N. Ética empresarial. Revista Praia Vermelha, Rio de Janeiro, v. 11, n. 1, p, 148-166, 2004.

LEVY, N. Ética e história. Rio de Janeiro: Relume Dumará, 2004.

MARX, K. Para a crítica da economia política. São Paulo: Abril Cultural, 1985. (Os Pensadores).

Manuscritos econômico-filosóficos. São Paulo: Boitempo, 2004.

MILLS, C. W. Sobre o artesanato intelectual e outros ensaios. Tradução de Maria Luiza de Barros. Rio de Janeiro: Zahar, 2009.

NUNES, B. (Org.). A crise do pensamento. Belém: UFPA, 1994.

Concha existencial. Revista Cult, n. 141, São Paulo: Bregantini, 2009.

PAUlO NETTO, J. A Construção do Projeto ÉticoPolítico do Serviço Social frente à crise contemporânea. In: Capacitação em Serviço Social e Política Social. Módulo 1 - Brasília, ABEPSS/CFESS, 1999.

PEREIRA, O. O que émoral. São Paulo: Brasiliense, 1991.

ROMANO, R. Contra o abuso da ética e da moral. Educação e Sociedade, Campinas, v. 22, n. 76, p. 94-105, 2001. Número especial.
SARMENTO, H. B. de M. Bioética, Direitos Sociais e Serviço Social. Belém: Unama, 2005.

. Interfaces entre bioética e políticas públicas. A medicalização dos estados de ânimo. In: CAPONI, S. et al. Medicalização da vida: ética, saúde pública e indústria farmacêutica. Palhoça: Unisul, 2010.

STEIN, E. Epistemologia e crítica da modernidade. Ijuí: Ed. Unijuí, 1997.

TEIXEIRA, J.; BRAZ, M. O projeto ético-político do Serviço Social. Serviço Social: direitos sociais e competências profissionais. Brasília: CFESS/ABEPSS, 2009.

VARES, L. P. A ética e o trabalho em Marx. In: BOMBASSARO, L. C. (Org.). Ética e trabalho: cinco estudos. Caxias do Sul: De Zorzi, 1989.

VÁZQUES, A. S. Filosofia da práxis. Rio de Janeiro: Paz e Terra, 1977.

Ética. Rio de Janeiro: Paz e Terra, 1978.

\section{Notas}

1 É importante destacar o risco de uma simplificação das capacidades do ser humano, seja na redução de sua potencialidade como sujeito histórico, que se produz e reproduzenquanto tal, seja em sua supervalorização enquanto vontade e desejo, restringindo os condicionantes societários. Estas duas possibilidades postulam que os fundamentos da realidade humana são ideais, estimulando novos simulacros desta idealização. Um instigante estudo crítico sobre esta questão podemos encontrar em Levy (2004).

2 Registramos nosso profundo sentimento e nosso agradecimento a Benedito Nunes, um amazônida, cidadão do mundo, capaz de aglutinar "existencialmente" a profundidade e a complexidade do conhecimento com a simplicidade e a humildade do viver humano, exemplo de ética e política, expressão da sabedoria, referência intelectual nacional e internacional, nas áreas da crítica literária, arte e filosofia, falecido em 27 de fevereiro de 2011 (momento em que escrevíamos este texto e o tomavámos como referência). Obrigado, Professor!

3 Bomba atômica. Termo utilizado pelos hibakusha, pessoas afetadas pela explosão atômica, em respeito aos mortos, ao invés de aos sobreviventes (HERSEY, 2002).

4 Algumas das ideias apresentadas sobre os filósofos citados podem ser encontradas em dois textos introdutórios, utilizados como referência, que tratam da história e dos fundamentos daética: Vázquez(1978)eChauí(1994). Também foi utilizado como fonte, o texto de Camps (1989). 
5 Eminstigante texto encontramos uma clara vinculação destas dimensões (ética e política) à profissão “todo projeto e, logo, toda prática numa sociedade classista têm uma dimensão política [...] se desenvolvem em meio às contradições econômicas e políticas engendradas na dinâmica das classes sociais antagônicas" e "[...] não há dúvidas de que o projeto ético-político do Serviço Social brasileiro está vinculado a um projeto de transformação da sociedade" (TEIXEIRA; BRAZ, 2009, p. 188).

\section{Hélder Boska de Moraes Sarmento}

hboska@yahoo.com.br

Doutor em Serviço Social pela PUC-SP

Professor do Curso de Serviço Social e Coordenador do Programa de Pós-Graduação em Serviço Social, Universidade Federal de Santa Catarina (PPGSSUFSC)

UFSC - Programa de Pós-Graduação em Serviço Social

Campus Universitário Reitor João David Ferreira

Lima

Bairro Trindade

Florianópolis - Santa Catarina

CEP: 88010-970 